\title{
A Study on Musical Preference and Styles of Personality among Young Adults
}

\author{
Mr. Vigraanth Bapu K G, Assistant Professor, Department of Psychology, Kristu Jayanti College, \\ Bangalore, India, vigraanth @kristujayanti.com \\ Nochilu Curha, Post Graduate Student, Department of Psychology, Kristu Jayanti College, \\ Bangalore, India, curhanochi@gmail.com
}

\begin{abstract}
Personality is a set of behaviors that make each one of us unique and it differentiates us from others and leads us to act consistently in various situations. Music being a multi-dimensional phenomenonhas been designed on several levels which affect people in various ways from emotion regulation to cognitive development, along with providing a means for self-expression. The present study focuses on the Musical Preference and Styles of Personality among 63 Young Adults from Bangalore and Nagaland, between the age group of 18 to 30 . The objectives of this descriptive research study include the study of the styles of personalities among young adults, to study the music preferences of young adults, and to know the relationship between music preference and personality. NEO-Five Factor Inventory 3 (NEO-FFI-3) and Short Test on Music Preferences (Revised, STOMPR) scale was administered through Google Classroom.s
\end{abstract}

Keywords: Musical Preference, Personality, Young Adults

\section{INTRODUCTION}

The American Psychological Association defines personality as individual differences in characteristic patterns of thinking, feeling, and behaving (2017). [18] Personality perseveres characteristic that create consistency and independence in everyone. It incorporates behaviours that make each one of us interesting and it differentiates us from others. Since time immemorial, people have battled to understand personality. Various theories have been created to clarify identity development and its impacts on ones behaviour. One such theory was proposed by a psychologist named Raymond Cattell.16 Personality Factor did not begin within the clinical settings. His approach was rather logical, which depended mainly on the observation of behaviours and masses of information (Cattell, 1970). Cattell adhered to evidences determined from experimental research.

[4] Cattell (1965) identified 16 source traits as the basic factors of personality. These sources of traits were best known in the form in which they were most used in a personality test called the Sixteen Personality Factor (16 $\mathrm{PF})$. The $16 \mathrm{PF}$ Test is widely used to assess personality for research, clinical diagnosis, and predicting occupational success. Some of the factors that the $16 \mathrm{PF}$ test can predict efficiently were, it can predict marital stability, Yielded results indicating that some source traits are primarily inherited while others are determined primarily by environmental influences, can identify 16 source traits of personality and can be used for research, clinical diagnosis, and predicting success on the job.
[5], [19] Another theory widely used by psychologists to understand personality is the Big Five Factor by McCrae and Costa embarked on an extensive research program that identified five so-called robust or Big Five factors(McCrae \& Costa, 1985, 1987).

Extraversion, Agreeableness, Conscientiousness, Neuroticism and Openness to Experience are a set of five broad trait dimensions that constitute the most widely used model of personality structure.

Extraversion represents individual differences in assertiveness and energy level. Highly extraverted individuals enjoy socializing with others and are comfortable expressing themselves in group and frequently experience positive emotions such as enthusiasm and excitement.

Agreeableness captures differences in compassion and possesses respectfulness. They also experience emotional concern for others' well-being and regard people for their personal rights and preferences, and generallyhold positive beliefs about others.

Conscientiousness, individuals differ in the ideas of organization, productiveness, and responsibility and prefer order and structure; they work constantly to pursue their goals and are committed to fulfilling their duties and goals.

Neuroticism represents the differences in the frequency and intensity of negative emotions and are more prone to experience such as anxiety, sadness, and mood swings 
Openness to Experiencerepresents variance in intellectual curiosity, aesthetic sensitivity, and imagination. They are sensitive to art and beauty, and often generate original ideas.

\section{A. Musical preference}

Personality also leads us to act consistently in various situations and music for multi-dimensional phenomena, have been designed on several levels that affect people in various ways from emotion regulation to cognitive development, along with providing a means for selfexpression. Music can bring out strong emotions. Even sports teams are more likely to play hard rock or rap before a game because most people can figure out the reason behind those musical choices. Music is so influential on the brain that the type of music we listen to actually has the ability to change the way you think and look at the world. All over the world and all through the history individuals used music to express their internal sentiments, be it sad or happy. Besides variation in music, contrast with respect to the choices of music. People report incredible effect of music on them, mentally and physiologically. The thought that music can and affects individuals is a more than an unimportant guess, but the mechanisms involved in determining human response have not been clearly identified (Hahn, 1954). The fundamental issue centers on the address of whether human reaction to music is basically logical in terms of characteristic properties of the music. Research on how personality influences and the response of the listener to music has generally focused on individual preference for a type of music. Another important dimension of the human response to music is related to the meaning of music. Music plays an important role in the lives of people the entire world, which is why many wonder what individual factors might influence musical preferences. [2] Perhaps America's most persuasive commitment to the world of popular music has been the development of rock and roll in the 1950s. Numerous streams of society and vernacular music styles, including blues, spirituals, gospel, numbers, hillbilly music, and early jazz, contributed to the evolution of rock and roll (R\&R). But it was the meeting of African American rhythm and blues and Anglo American honky-tonk (country) music that led to the development of a distinctive modern fashion that would overwhelm the field of well-known music in postWorld War II America. The music highlighted the tense, nasal vocal style related with the earlier ballad tradition, went with by twangy guitars and fiddles, and verses centered on stories of loneliness and broken love relationships. Singers like Muddy Waters a.k.a "father of modern Chicago blues", Howlin' Wolf, and B. B. King yelled and pleaded to their audiences, supported by screaming electric guitars, intensified harmonicas, and rhythm areas of drums, bass, and piano. The music was loud, aggressive, and sensual, with verses bragging of sexual victory or lamenting failed love. The earliest rockand-roll recordings were made by both white and black artists in the mid-1950s. Thus, R\&R was the inevitable result of an interracial musical stew that had been simmering within the southern United States for a few centuries. R\&R started to expand mindfulness of black culture. $R \& R$ was a popular fashion made within the studio and promoted specifically for armies of youthful, predominantly white customers who, much obliged to serious music is characterized by the formally and artistically more sophisticated and enduring types of music, as distinguished from popular, folk, and jazz. Serious music includes symphonies, operas, etc. Serious music is usually referred to as "classical" music. Classical music refers to a musical form written and performed during the latter half of the 18th and early 19th centuries. From a broader perspective, classical music has come to be viewed by the public as a form of serious, sophisticated, and complex music, irrespective of specific music time periods. Popular music may be conceptualized as a readily available form of music geared toward mass consumption at a given time. It is characterized by relatively simple and repetitive melodies usually with lyrical content. Popular music is seen as an expression of contemporary popular culture and is a less enduring musical form than classical music. Some of the most listened music genres are Alternative, classical, blues, rock/metal, country, dance/edm, hip-hop / rap, pop and indie. Pieces of happy/sad music can influence us, and a study proves that after hearing a brief piece of music, individuals were more likely to see a neutral expression as cheerful or pitiful, as such coordinating the tone of the music they had listened and this, in turn, influences their way of dealing with a circumstance with higher levels of certainty. Building self-confidence is the first step to success and for that we unquestionably require music. It's a proven that attending to music concerts contributes a lot in lifting one's confidence level. The data indicated that people consider music an important aspect of their lives and listening to music an activity they engaged in frequently.

[6] Wesley Geer in 2012 initiated a musical program called Rock to Recovery, to help young adults suffering from addictions. Once a week, at Promises West Los Angeles, a residential addiction treatment center, young adults gather for a jam session led by a professional rock musician. Each person picks out an instrument, and together they create a song, perform it and record it called Rock to Recovery, the founder of the band Hed PE and former guitarist for legendary nu-metal band Korn. "From my own experience in rehab, I know how powerful music can be in recovery," says Geer, who has been sober for nearly a decade. "Music enabled me to relax and 'check out' without drugs; it lifted my spirits in ways I can't even explain."

Today, Rock to Recovery has 17 clients at 30-plus facilities in the U.S. - and even Geer is surprised by how popular the sessions have become at Promises and elsewhere. "Once I saw the power that even a little pink shaker has on someone struggling with recovery, I knew I was on to 
something," he recalls. "Time after time, I watch people's spirits change as they bond as a group and learn to do things, they never thought possible - like shred a guitar".

\section{B. Young adults}

[1] Adulthood is a more troublesome and stressful stage, adolescence, ages 14 to 23. Emotional disorders and delinquency may be evident as young people experience conflicts centeredon the drives for independence, selfassertion, and sex.Early adulthood is, for most people, the time of physical capacity. The body reaches full height by the late teens, and physical strength increases into the late 20s and early 30s (Whitbourne, 2001). During adulthood change is imminent, even in basic capacities. Some decline in the perception of high-pitched tones is found by the late 20s (Whitbourne, 2001), and manual efficiency begins to reduce in the mid-30s. Generally, people in early adulthood feel robust and energetic, at the same time it is usual to observe fluctuations around deadlines and exams. On the other hand, people in this age group are also legally able to use harmful substances, such as alcohol and tobacco, illegal stimulants, or narcotics. The health status and prospects of young adults are dependent more than ever before on their own behavioural choices. Similarly, their way of dressing is mainly influenced by the type of music one listens to unless rules are imbedded on them. For instance, a person who listens to pop or popular music may dress up in funky way, they are usually follow the newest trends of fashion, whereas the individuals who listen to rock and roll may be dressed in ripped jeans, may have tattoos and piercings on their bodies. All these factors are influenced by their choice in music and the inspirations they draw from their idols.

Cognitive development in adolescence is likely at a higher range, most people are capable of the levels of reasoning that is expect for normal functioning in adult society. Although there are wide individual differences in attainment, most young adults are able to deal with cognitive tasks in a more abstract way than before, and to attain solutions to problems by comparing possible explanations.

Social and emotional development is observed among the young adults, they face some formidable developmental tasks, and most people at the beginning of this stage are concerned with launching a career. They may be studying to gain the critical qualifications, or training at the entry level of an organization. At the same time, young adults tend to be finding their way through the world of romance, which can also lead to stress and anguish. All of this happens alongside changes in relationships with parents, and the increasing expectation that the young person will take responsibility for one's own life. For most people, facing these issues brings a range of emotional reactions.

\section{REVIEWS OF LITERATURE}

[17] Rentfrow and Gosling (2003) conducted a study on 3,500 individuals to examine their differences in musical preferences to reveal 4 music-preference dimensions: Reflective and Complex, Intense and Rebellious, Upbeat and Conventional, and Energetic and Rhythmic. Results showed that preferences for these music dimensions relating to a wide array of personality dimensions (e.g., Openness), self-views (e.g., political orientation), and cognitive abilities (e.g., verbal IQ). [14] Papinczak, Dingle, Stoyanov, Hides and Zelenko (2015) conducted a study to study the relationships between young people's use of music and their well-being, on $\mathrm{N}=11$ participants aged 15 25 years. Results revealed well-being to music listening in four ways: relationship building, modifying emotions, modifying cognitions and emotional immersion.[16] Rentfrow and Gosling (2016) conducted two studies, which showed that individuals use their music preferences to communicate information about their personalities to observers, and that observers can use such information to form impressions of others. Study 1 revealed that music was the most common topic in conversations among strangers given the task of getting acquainted. Study 2 showed that (a) observers were able to form consensual and accurate impressions on the basis of targets' music preferences, (b) music preferences were related to targets' personalities, (c) the specific cues that observers used tended to be the ones that were valid, and (d) music preferences reveal information that is different from that obtained in other zero-acquaintance contexts. The final result focused on the mechanisms that may underlie the links between personality and music preferences. [9] Karajgi and Shah (2017) conducted a cross-sectional study in young adults aged between $18-24$ years to explore the effect of various music types and personality type on Semantic Memory Retrieval. Results suggested that participants performed the fastest while instrumental music was played and no significant difference in personality was found. [11]Murtonen (2018) conducted a study on $\mathrm{N}=278$ to find the spirituality formation focusing on young adults based on the role of spiritual music. The study resulted that young adults' spirituality formation was enhanced by music, results also show that music strengthen confidence, advanced spiritual connection with other people.[4] Cherry (2018) from Heriot-Watt University conducted a large-scale study on 36,000 participants worldwide and were asked to rate more than 104 different musical styles and offering information about aspects of their personalities. Result suggested that people define themselves through music and use it to relate to other people. [13] Nave et al., (2018) conducted two studies on musical preferences and personality. Study 1 consisted of $n=22,252$ participants which indicated that unfamiliar musical excerpts resulted individual differences in personality- particularly openness and extraversion. Study 2 consisted of $N=21,929$ participants, results suggested that naturally occurring behaviour and facebook likes for musical artists, predicted individual differences in personality. General results of the study helped in establishing the robustness and external 
validity of the links between musical preferences and personality.

\section{METHOD}

\section{A. Research Design}

Research design is a systematic plan, structure, and strategy in directing the research. The present study was done using a Cross-Sectional research design with a quantitative approach, this method is expressed in numbers and graphs. It is used to test or confirm theories and assumptions. This type of research can be used to set up generalized facts about a topic and propose to analyze my data using measures of correlation and t-test.

\section{B. Statement of the problem}

The main aim of the study is to find out the different personality types based on one's choice of music among youngadults. Many studies have been conducted on personality types based on musical choice but since there is very less studies conducted on young adults, there arises a need for study on young adults.

\section{Objectives of the study}

1. To know the relationship between music preference and personality.

\section{Hypothesis}

H1. There exists a significant relationship between the Big Five factors and Music Preference.

\section{E. Operational Definition}

Types of Music:

\section{1) Reflective and Complex}

The genres under Reflective and Complex were blues, jazz, classical, and folk music. The participants scoring high on these genres indicated to facilitate introspection and are structurally complex

\section{2) Intense and Rebellious}

The genres under Intense and Rebellious were defined by rock, alternative, and heavy metal music. The participants who scored high on these genres indicated full of energy and emphasize themes of rebellion.

\section{3) Upbeat and Conventional}

The genres under Upbeat and Conventional were defined by country, sound track, religious, and pop music. The participants who scored high on these genres indicated that participants emphasize positive emotions and are structurally simple.

\section{4) Energetic and Rhythmic}

The genres under Energetic and Rhythmicwere defined by rap/hip-hop, soul/funk, and electronic/ dance music. The participants who scored high on these genres indicated that participants are lively and often emphasize the rhythm.

[12] Big 5 Factor Personality:

\section{1) Neuroticism}

Indicates a person's ability to remain stable and balanced.

2) Openness

Indicates how open-minded and authority-challenging an individual is.

\section{3) Agreeableness}

Indicates how warm, friendly, and tactful an individual is.

\section{4) Conscientiousness}

Indicates how self-disciplined and organized a person is.

5) Extravaersion

Indicates how outgoing and social a person is.

\section{F. Variables}

1. Personality Styles

2. Music Preference

\section{G. Demographic variables}

1. Age.

2. Gender.

3. Musical instrument owned by the participant.

4. Which event the participant is most likely toattend?

\section{H. Universe of the study}

The study was conducted on Young Adults between ages 18-30 to find relation between Personality and Musical Preferences and data collection is done majorly on students.

\section{Sample and techniques}

A non-probability sampling of purposive sampling technique was used for this study. The research was done by approaching 63 young adults between the ages 18-30 from Bangalore and Nagaland. Google forms and questionnaire method were used to collect data. Respondents were informed that participation was voluntary, and that the information provided by them in the questionnaire will be confidential. The participants were requested to answer the questions with complete honesty and were supposed to be as reliable as possible. They were also informed that there was no definite time limit to finish the questionnaires.

\section{J. Research ethics followed}

[15] Research ethics provides rules for the accurate conduction of research. It is applied in all stages of research, such as planning, conducting and evaluating a research project.

- The researcher avoided risks of harming people, the environment, or property unnecessarily.

- Research did not use any source of deception on individuals participating.

- The researcher obtainedinformed consent from all participants involved in the study. 
- The researcher assured confidentiality to the participants

\section{K. Tools for the study}

- [3] The NEO FFI-3 is especially useful when time is limited and global information on personality is considered sufficient. The NEO-FFI can help you understand an individual's basic emotional, interpersonal, experiential, attitudinal, and motivational styles.

- The STOMPR has good internal consistency with alpha reliability ranging from .70 to .81

\section{Description of the tool}

Short Test on Music Preferences - Revised(STOMPR)

Developed by Gosling and Rentfrow (2011). The STOMPR is a revised version of the STOMP scale assessing preferences for 23 genres of music. Each to be rated on a seven-point scale ranging from 'dislike strongly' (1) to 'like strongly' (7). The following factors are described as:

Factor 1 was blues, jazz, classical, and folk music-genres that seem to facilitate introspection and are structurally complex-and this factor was named Reflective and Complex.

Factor 2 was defined by rock, alternative, and heavy metal music-genres that are full of energy and emphasize themes of rebellion-and was named Intense and Rebellious.

Factor 3 was defined by country, sound track, religious, and pop music-genres that emphasize positive emotions and are structurally simple — and was named Upbeat and Conventional.

Factor 4 was defined by rap/hip-hop, soul/funk, and electronica/ dance music-genres that are lively and often emphasize the rhythm - and was named Energetic and Rhythmic

\section{NEO- FIVE FACTOR INVENTORY-3 (NEO-FFI-3)}

[5] The NEO-FFI-3 is a 60-item version of the NEO-PI-3 that provides a quick, reliable, and accurate measure of the five domains of personality (Neuroticism, Extraversion, Openness, Agreeableness, and Conscientiousness). It was invented by Paul Costa and Robert McCrae. Each statement had to be rated on a five-point scale ranging from 'strongly disagree' (1) to 'strongly agree' (5).

Neuroticism: Neuroticism is the foremost unavoidable space of personality scales which contrasts alteration or emotional stability with maladjustment or neuroticism.

Extraversion: Individuals who score high on extraversion are social, like people and prefer huge bunches and gathering. The aspects of extraversion are warmth, gregariousness, self-assuredness, action, excitementseeking, positive feelings
Openness: As a major measurement of identity, $O$ is dynamic creative energy, tasteful affectability, and mindfulness to inner feeling, inclination for assortment, mental interest, and freedom of judgment. The aspects of openness to involvement are fantasy, aesthetics, sentiments, activities, thoughts, and values.

Agreeableness: Agreeableness is fundamentally a measurement of interpersonal tendencies. The aspects of agreeableness are trust, straightforwardness, charitableness, compliance, humility, and tender mindedness.

Conscientiousness: Self-control also can refer to more active process of planning, organizing, and carrying out tasks, individual differences in this tendency are the basis of Conscientiousness

\section{Descriptive statistics}

The descriptive statistical tools used for the study are mean (to study the average), standard deviation (to find the deviation of the variables) and range.

\section{N. Inferential statistics}

Inferential statistics permits the researcher to create predictions (inferences) from the obtained information. With inferential statistics, the researcher takes information from samples and generalizes about a population.

The inferential statistical tools used for the study is correlation (Pearson Correlation). It is a way to find relationship between two sets of variables.

\section{ANALYSIS AND DISCUSSION}

Table 1: Showing the frequency of the profile of the respondents

\begin{tabular}{|c|c|c|}
\hline Criterion & Characteristics & Percentage (\%) \\
\hline \multirow{2}{*}{ Gender } & Male & 24 \\
\cline { 2 - 3 } & Female & 74 \\
\hline \multirow{2}{*}{\begin{tabular}{c} 
Preferred event \\
\cline { 2 - 3 }
\end{tabular}} & Play & 15 \\
\cline { 2 - 3 } & Concert & 57 \\
\hline $\begin{array}{c}\text { Musical instrument } \\
\text { owned }\end{array}$ & Basketball game & 27 \\
\cline { 2 - 3 } & Yes & 36 \\
\hline
\end{tabular}

Table 1 shows the frequency distribution profile of the respondents. The result shows that there are more female (74\%) participants as compared to male (24\%) participants. The result also shows that the participants when asked which events they are most likely to attend, majority of the participants opted for concert(57\%), 27\% of the participants opted for basketball games and the remaining $15 \%$ opted for play. Finally, the results show that $63 \%$ of the participants did not own any musical instrument, while the rest $36 \%$ of the participants owned musical instruments. 
Table 2: Showing the descriptive status of the dependent variables

\begin{tabular}{|c|c|c|c|}
\hline Dimensions & $\mathrm{N}$ & Mean & SD \\
\hline $\mathrm{N}$ & 63 & 38.11 & 6.75 \\
\hline $\mathrm{E}$ & 63 & 37.48 & 5.12 \\
\hline $\mathrm{O}$ & 63 & 40.44 & 4.80 \\
\hline $\mathrm{A}$ & 63 & 40.90 & 5.13 \\
\hline $\mathrm{C}$ & 63 & 42.17 & 5.01 \\
\hline Intense and Rebellious & 63 & 4.25 & 1.21 \\
\hline Reflective and Complex & 63 & 4.59 & 0.81 \\
\hline Upbeat and Conventional & 63 & 5.17 & 0.88 \\
\hline Energetic and Rhythmic & 63 & 4.80 & 1.02 \\
\hline
\end{tabular}

Table 2 shows the calculation of measures of central tendencies of the five factors of personality and musical preferences. The mean for each factor of personality are Neuroticism, Extraversion, Openness, Agreeableness and Conscientiousness. N (38.11), E (37.48), O (40.44), A (40.90) and $C$ (42.17). The mean for each factors of musical preferences are Intense and Rebellious (4.25), Reflective and Complex (4.59), Upbeat and Conventional (5.17) and Energetic and Rhythmic (4.80) respectively.

The standard deviation for each factor of personality is $\mathrm{N}$ (6.75), E (5.12), O (4.80), A (55.13) and C (5.01) and the SD scores for each factor of musical preference are Intense and Rebellious (1.21), Reflective and Complex (.81), Upbeat and conventional (.88), and Energetic and rhythmic (1.02) respectively.

Table 3:Showing the correlation between Personality and Musical Preferences

\begin{tabular}{|c|c|c|c|c|c|}
\hline & $\mathrm{N}$ & $\mathrm{E}$ & $\mathrm{O}$ & $\mathrm{A}$ & $\mathrm{C}$ \\
\hline $\mathrm{I} \& \mathrm{R}$ & -.077 & $\mathbf{. 3 3 5}^{* *}$ & .123 & .222 & .158 \\
\hline $\mathrm{R} \& \mathrm{C}$ & -.133 & $\mathbf{. 2 4 9}^{*}$ & $\mathbf{. 2 7 5}^{*}$ & $\mathbf{. 2 7 2}^{*}$ & $\mathbf{. 3 9 8}^{* *}$ \\
\hline U\&C &. $\mathbf{3 0 1}$ & .032 & $\mathbf{. 3 8 5}^{* *}$ & .172 & .185 \\
\hline E\&R & -.054 & $\mathbf{. 3 7 0}^{* *}$ & $\mathbf{. 3 9 3}^{* *}$ & $\mathbf{. 2 8 2}^{*}$ & $\mathbf{. 3 5 9}^{* *}$ \\
\hline
\end{tabular}

Note: $\mathrm{N}$ - Neuroticism, E - Extroversion, O - Openness, A - Agreeableness, C - Conscientiousness, I\&R - Intense and Rebellious, R\&C - Reflective and Complex, U\&C Upbeat and Conventional, E\&R - Energetic and Rhythmic

Table 3 shows the correlation between the Big Five Personality Factors and the participants Preference of Music.

\section{Intense and Rebellious}

The dimension of Extraversion was the only personality dimension which had a positive relationship with Intense \&Rebellious music $(r=0.335, \mathrm{p}<0.01)$. The result is similar to the findings presented in a study conducted by [10] Lanmeyer (2012) which suggests that extraverted individual preferred more of Intense \& Rebellious music. The preference of Intense \& Rebellious music is high among Extraverts because of the energy involved in the music. In contradiction to this finding, a study revealed a negative correlation between extraversion and preference of Rock music (equal to intense and rebellious music) and also said that extraverts were found to predict changes in preference for Rock music, i.e. an individual who had higher initial levels of Extraversion tended to report higher rates of decrease in preference for Rock music over time (Desling et. al., 2007).

\section{Reflective and Complex}

Table 3 shows that the musical preference of Reflective and Complex has a correlation with all the personality dimensions except Neuroticism. Between Reflective \&Complex music and Extraversion $(\mathrm{r}=0.249, \mathrm{p}<0.05)$, Openness ( $\mathrm{r}=0.275, \mathrm{p}<0.05)$, Agreeableness $(\mathrm{r}=0.272, \mathrm{p}$ $<0.05)$, and Conscientiousness ( $r=0.398, \mathrm{p}<0.05)$.

The current finding of is similar to the findings reported in the studies conducted by various authors All the studies had found a positive correlation between Openness and Reflective \& Complex musical preference. They suggest that individuals who enjoy listening to reflective and complex music tend to be inventive, have active imaginations, value aesthetic experiences, consider themselves to be intelligent, tolerant of others, and reject conservative ideals. [7] (Rentfrow\& Gosling, 2003; Desling et. al. 2008; George et. al., 2007; Zweigenhaft, 2008).

Desling et. al. (2003) found that there is positive relationship between Conscientiousness and choice of Elite music (Similar to Reflective and Complex music) especially among the younger age groups. Individuals wit Conscientiousness personality generally tend to be orderly, persistent, strong-willed, and determined these traits make them prefer more of Jazz and Classical music.

Similar to the current study another study also revealed that there is a significant positive relationship between Agreeableness and choice of Elite music. The study suggests that compassion for others may also be reflected in the lyrics of religious

or gospel music (Reflective \& Complex music), which may account for the positive association that was found between Agreeableness and the Elite dimension (Desling et. al., 2003)

The positive correlation between Extraversion and Reflective \& Complex music as found in this study was not supported by most of the studies. Many studies generally showed low correlation with no significance.

\section{Upbeat and Conventional}

Only Neuroticism and Openness Personality dimensions had significant correlation with Upbeat \& Conventional musical preference. Table 3 shows a positive correlation between Upbeat \& Conventional Music preference and Neuroticism $(\mathrm{r}=0.301, \mathrm{p}<0.05)$ and Openness $(\mathrm{r}=0.385, \mathrm{p}$ $<0.01)$.

Few studies which were conducted previously were found to have a Negative Correlation between Openness and Upbeat \& Conventional Music preference, which goes against the finding of the current study (Rentfrow\& 
Gosling, 2003, Desling et. al, 2007). The reason behind it could be that an individual who is open to new experience may also be open to new and complex musical experience, thus regardless of the genre of music, when it is new and unknown to one, they might engage in listening to such music. It is also shown that individuals who prefer Upbeat \& Conventional music tends to be cheerful, socially outgoing, and reliable (Rentfrow\& Gosling, 2003).

This study shows a positive correlation between Neuroticism and Upbeat \& Conventional music. The reason why they prefer that music could be due to the lyrics. The lyrics in the Upbeat and Conventional dimension were perceived as simple and direct, low in negative affect, but high in positive affect and energy level. Thus, to increase the energy level and feel more positive individuals with Neuroticism prefer Upbeat \& Conventional music (Rentfrow\& Gosling, 2003).

\section{Energetic and Rhythmic}

Like Reflective and Complex musical preference here also the participants had all the personality dimension except for Neuroticism. Between Reflective \&Complex music and Extraversion $(\mathrm{r}=0.370, \mathrm{p}<0.01)$, Openness $(\mathrm{r}=0.393, \mathrm{p}$ $<0.01)$, Agreeableness $(\mathrm{r}=0.282, \quad \mathrm{p} \quad<0.05)$, and Conscientiousness $(\mathrm{r}=0.359, \mathrm{p}<0.01)$.

Rentfrow and Gosling (2003) showed a similar result in their study where they found a positive correlation between the personality dimensions of Extraversion, Agreeableness, and Energetic and Rhythmic musical preference.A similar results were reported by Zweigenhaft (2008), where he found a significant positive correlation with Extraversion and negative correlation with Agreeableness. These individuals who enjoy Energetic and Rhythmic music tend to be talkative, full of energy, are forgiving, see themselves as physically attractive and tend to eschew conservative ideals, these are also some of the traits of the above mentioned personality (Rentfrow and Gosling, 2003).

[20] A Study by Zweigenhaft(2008) found a significant positive correlation between Openness and preference of Energetic \& Rhythmic music similar to our study here. [8] Previous studies have shown a significant negative correlation between Conscientiousness and Energetic and Rhythmic which is going against the findings of the current study (George, 2007).

\section{SUMMARY AND CONCLUSION}

The study was conducted with an aim to examine the relationship between the preferences of music and personality dimensions among young adults. The data collected through Google Forms and Hard copies were entered into SPSS for further statistical calculations. Correlations was carried out between the preference of music dimensions and measures of personality. The results show that there is a significant relationship between Neuroticism and preference of U \& C music, Extraversion and I \& R, R \& $\mathrm{C}$ and $\mathrm{E} \& \mathrm{R}$, Openness and $\mathrm{R} \& \mathrm{C}, \mathrm{U} \& \mathrm{C}$ and $\mathrm{E} \& \mathrm{R}$, Agreeableness and $\mathrm{R} \& \mathrm{C}$ and $\mathrm{E} \& \mathrm{R}$ and Conscientiousness and $\mathrm{R} \& \mathrm{C}$ and $\mathrm{E} \& \mathrm{R}$. These correlations reveal a fascinating pattern of links between music preferences and personality. To conclude, we can say that the hypothesis states that there is a significant correlation between the Big Five factors and Music Preference. Hence, the hypothesis is accepted. The results of the current study were very similar to the classical study conducted by Rentfrow and Gosling (2003). Most of the results do match with other studies conducted before, interestingly this study also has revealed new dimensions for further studies.

\section{IMPLICATIONS}

The present study can help understand an individual's basic emotional, interpersonal, experiential, attitudinal, and motivational styles based on various dimensions of music. Thus, we could use the findings of the study and encourage individuals to listen to a genre of music to bring in a change in their behaviour. The findings of this study could also be used in music therapy, here the study has brought out a clear-cut idea on the relationship between Personality and musical preference.

\section{REFERENCES}

[1] Whitbourne,S.K. (2001), Durkin.k, “Adolescence and Adulthood" 10. (n.d.). Retrieved from http://www.blackwellpublishing.com/intropsych/pdf/chapte r10.pdf

[2] Allen, R., Hager , N., Cohen, D., \& Taylor, J. (2015). Music: Its Language, History, And Culture. Retrieved from https://libguides.brooklyn.cuny.edu/music1300

[3] Bedi, Suhani.

"NEO-FFI-3

Interpreation." Academia.edu,https://www.academia.edu/49 06689/NEO-FFI-3_Interpreation.

[4] Cherry, K. (2019, June 16). Analyzing Personality Factors for Counseling and Career Guidance. Retrieved from https://www.verywellmind.com/cattells-16personality-factors-2795977

[5] Costa, P. T., \& McCrae, R. R. (2010). NEO Five Factor Inventory-3 (NEO FFI-3) | ACER. Retrieved from https://shop.acer.edu.au/the-neotm-inventories-neotm-fivefactor-inventory-3-neotm-ffi-3

[6] Cromley, J. (2015, August 17). Rock Musicians Strike a Chord with Young Adults in Recovery. Retrieved from https://www.addiction.com/blogs/rock-musiciansstrike-chord-young-adults-recovery/

[7] Delsing, M. J. M. H., Bogt, T. F. M. T., Engels, R. C. M. E., \&Meeus, W. H. J. (2008). Adolescents music preferences and personality characteristics. European Journal of Personality, 22(2), 109-130. doi: $10.1002 /$ per.665 
[8] George, D., Stickle, K., Rachid, F., \&Wopnford, A. (2007). The association between types of music enjoyed and cognitive, behavioral, and personality factors of those who listen. Psychomusicology: A Journal of Research in Music Cognition, 19(2), 32-56. doi: 10.1037/h0094035

[9] Karajgi, A. and Shah, K. "Effect of music and personality on semantic memory retrieval in young adults," International Journal of Advanced Research, vol.5, no3, pp.1400-1403, 2017

[10] Langmeyer, A., Guglhör-Rudan, A., \&Tarnai, C. (2012). What Do Music Preferences Reveal About Personality? Journal of Individual Differences, 33(2), 119130. doi: 10.1027/1614-0001/a000082

[11] Murtonen, S. "The role of music in young adults' spiritual development." International Journal of Childrens Spirituality, vol.23, no2, pp 209-223. doi: 10.1080/1364436x.2018.1449737, 2018

[12] "NEO Five-Factor Inventory - 3." SIGMA Assessment Systems,

https://www.sigmaassessmentsystems.com/assessments/neo -five-factor-inventory-3/

[13] Nave, G., Minxha, J., Greenberg, D. M., Kosinski, M., Stillwell, D., \&Rentfrow, J. "Musical Preferences Predict Personality: Evidence From Active Listening and Facebook Likes. Psychological Science," vol.29, no.7, pp. 11451158. doi: 10.1177/0956797618761659, 2018.

[14] Papinczak, Z., Dingle, G., Stoyanov, S., Hides, L. and Zelenko, O. "Young people's uses of music for well-being." Journal of Youth Studies, vol.18, no.9, pp.1119-1134, 2015

[15] Research Guides: Research Methods: Ethics in Research. (n.d.). Retrieved from https://libguides.library.cityu.edu.hk/researchmethods/ethic $\mathrm{s}$ (thepsychemind.com)

[16] Rentfrow, P. J., \& Gosling, S. D. "Message in a Ballad." Psychological Science, vol.17, no.3, ppp.236-242. doi: 10.1111/j.1467-9280.2006.01691.x, 2006.

[17] Rentfrow, P. J., \& Gosling, S. D. (2003). The do re mis of everyday life: The structure and personality correlates of music preferences. Journal of Personality and Social Psychology, 84(6), 1236-1256. doi: 10.1037/00223514.84.6.1236

[18] Schultz, D. P., \& Schutz, S. E. "Theories of Personality” ED-10, pp. 212-219. USA, FL: Wadsworth, 2012.

[19] Soto, C. J. "Big Five personalities traits.” ResearchGate, PP.240-241, 2018

[20] Zweigenhaft, R. L. (2008). A Do Re Mi Encore. Journal of Individual Differences, 29(1), 45-55. doi: 10.1027/1614-0001.29.1.45 